\title{
IMMUNITY AND LONGEVITY
}

\author{
GYÖRGY CSABA* \\ Department of Genetics, Cell- and Immunobiology, Semmelweis University, \\ Budapest, Hungary
}

(Received: February 20, 2018; accepted: April 7, 2018)

The role of immune system is to protect the organism from the not built-in program-like alterations inside and against the agents penetrating from outside (bacteria, viruses, and protozoa). These functions were developed and formed during the evolution. Considering these functions, the immune system promotes the lengthening of lifespan and helps longevity. However, some immune functions have been conveyed by men to medical tools (e.g., pharmaceuticals, antibiotics, and prevention), especially in our modern age, which help the struggle against microbes, but evolutionarily weaken the immune system. Aging is a gradual slow attrition by autoimmunity, directed by the thymus and regulated by the central nervous system and pineal gland. Considering this, thymus could be a pacemaker of aging. The remodeling of the immune system, which can be observed in elderly people and centenarians, is probably not a cause of aging, but a consequence of it, which helps to suit immunity to the requirements. Oxidative stress also helps the attrition of the immune cells and antioxidants help to prolong lifespan. There are gender differences in the aging of the immune system as well as in the longevity. There is an advantage for women in both cases. This can be explained by hormonal differences (estrogens positively influences both processes); however, social factors are also not excluded. The endocrine disruptor chemicals act similar to estrogens, like stimulating or suppressing immunity and provoking autoimmunity; however, their role in longevity is controversial. There are some drugs (rapamycin, metformin, and selegiline) and antioxidants (as vitamins $\mathrm{C}$ and $\mathrm{E}$ ) that prolong lifespan and also improve immunity. It is difficult to declare that longevity is exclusively dependent on the state of the immune system; however, there is a parallelism between the state of immune system and lifespan. It seems likely that there is not a real decline of immunity during aging, but there is a remodeling of the system according to the claims of senescence. This is manifested in the remaining (sometimes stronger) function of memory cells in contrast to the production and number of the new antigen-reactive naive T-cells.

Keywords: immune system, lifespan, hormonal imprinting, endocrine disruptors, thymus, autoimmunity

*E-mail: csaba.gyorgy@med.semmelweis-univ.hu 


\section{Introduction}

It is well known that the elderly people are less resistant to infectious diseases, frequently develop cancers, and inclined to autoimmune diseases. These processes can be deduced to the progressing weakness of immune response. The general immune response really decreases with aging [1], and there are some theories that point to the central role of declining immune system on the general aging as well as to the lifespan [2-4]. However, it is not clear that whether the deterioration of the immune system is the cause of the general senescence or it becomes senescent as a part of the general aging of the organism. Either the former or the latter supposition is right, the production and function of immune cells could have a basic role in the process.

\section{Senescence of Immune Cell Production and Cell Pool}

The domino hypothesis of the age-associated immune deficiency declares that the process initiates with the involution of the thymus $[5,6]$. In this case, the number of naive T-cells in the periphery is reduced [7] with the proliferation of resident T-cells, which later stops the proliferation. This is followed by a decline in immune function, consequently the weakness of immune defense against infections and cancer [8]. In centenarians (aged between 92 and 107 years), the frequency of $\mathrm{T}$ lymphocytes was lower than that in young adults [9]. The decrease was more expressed in CD8 than in CD4+ cells, leading to a high $\mathrm{CD} 4 / \mathrm{CD} 8$ ratio, in older adults. The mitogenic response to phytohemagglutinin or concanavalin A and the number of B-cells, as well as the production of IgM in vitro, were also reduced. The aged people have vanishingly low numbers and percentages of naive CD8+ T-cells in the peripheral blood and the number of memory CD8+ T-cells is higher (the naive cells are differentiated into effector and memory cells) [10]. These types of changes are less manifested in the case of CD4+ naive T-cells and for B-cells, as well as for some elements of innate immunity (dendritic cells and neutrophils); however, all immune cells are touched to some degree. The age-dependent defects in T- and B-cell functions run parallel with the changes in the innate immune system (decrease in cell-mediated immune functions, as response to vaccination) [11-15]; however, the most immune parameters are well preserved in centanarians, where there is only a small reduction of $\mathrm{T}$ lymphocytes. Other observation [16] shows that in centenarians, there is a relatively small reduction of virgin and memory T-cells [16] and the ability of cells to proliferate after appropriate stimuli. In addition, healthy centenarian's immune cells (including NK cells and phagocytes) efficiently kill 
the target cells [17]. This does not indicate the loss of immune reactivity, but a remodeling of the immune system during the progressing age. Chemotaxis, phagocytosis, natural killer cell activity, and lymphoproliferation in neutrophils and lymphocytes of peripherial blood were studied and found to be decreased in elderly people [3]. However, not only the T-cell sort of immune cells are decreasing with age, but also the B-cells, especially naive B-cells [18]. Macrophages, which are the very important participiants of the innate immune system, also have age-related impairments [19]. Studies on chemotaxis, phagocytosis, NK cell activity, and proliferation of lymphocytes and neutrophils show that centanarians have these functions almost similar to middle-aged adults [3]. This means likely that a catastrophic decrease of the immune functions does not happen and instead a programmed remodeling, which meets immunity to the requirements of the given age.

Chronic stress or glucocorticoid exposure causes similar (but transient) immunosenescence as progressing age. This permits the supposition that the continuous attrition of immune cell producing organs as well as the alteration of hormonal system have a role in immunosenescence [20].

In conclusion, though there is a decline in the strength of immunity in aged people, the dominant process is not the loss of cells, but the restructuring (remodeling) of immune cell pool and by this, there is a dominance of structures other than in younger age [21-24]. This means that the immune response to new antigens is significantly declined, whereas to the earlier (recall) antigens are well recognized and antibody production is satisfactory [25]. There is also a restructuring between the innate and the adaptive immune system, which is manifested by the usable cell sorts [26, 27]. It seems to be likely that the immune system is not an operator of longevity, but rather a marker of the rate of aging and a predictor of longevity [28, 29].

The aging of the immune system is mainly responsible for the free radicals, which are produced by the mitochondria and the balance between the amount of free radicals and antioxidants, produced endogeneously or consumed from outer sites [28-30]. However, the state of the nervous and the endocrine systems also has a basic role in the regulation of aging of the immune system by a nervous-immune communication [31]. The defensive function of the immune cells, especially that of macrophages, requests the abundant production of free radicals, while their membranes are very sensitive to the oxidative stress, which is mainly compensated by the production of antioxidants [32]. The absence or not efficient amount of antioxidants leads to the deterioriation of innate immune system [33], consequently also the weakness of adaptive immune system, which could be responsible for the immunosenescence [28, 32]. 


\section{The Increase of Human Lifespan, Evolutionary Considerations}

As it was mentioned, the duty of the immune system is to defend the organism from inner and outer attacks caused by alterations in the genetically determined order (e.g., cancers) as well as to control and annihilate the intruders (such as bacteria, parasites, viruses, etc.). During evolution, the immune system developed according to the claims of the animals and served the function of defense until the reproduction time, as the establishment of the following generation had a primary importance. In the world of mammals, the aging is infrequent and unnecessary, and this was also the situation in the case of human up to our modern age. Some centuries ago, the average human lifespan was between 30 and 40 years in the more developed countries and less in underdeveloped cases. This situation is also found to be present in Africa, and only the more developed countries would be generally needed the immune defense after the reproductive ages. This can explain why is a deterioration of the immune system during aging or why is a reordering of this system to a virtually weak state during aging. However, the evolutionary legacy is only one of the factors, which impairs the immune system in elderly people. The other is the conveyance of human evolution to tools.

\section{Immunity and Conveyed Evolution}

In the past 40,000 years, the human morphological and functional evolution has stopped, although some signs of molecular evolution can be observed. Man conveyed its evolution to instruments (tools), which helps in the maintenance of life better than their original capabilities [34]). Man can move better using carriage, later by car, than by legs of their own and can see better using magnifiers, later microscopes, etc. Man developed vaccination to prevent infections and antibiotics to kill bacteria, if the disease had already manifested. Earlier, the memory of immune cells ensured the recognition of bacteria and this inhibited the novel manifestation of an infectious disease in the case of second infection, but the second manifestation is frequent today, which was because of the quick antibiotic treatment and there is not enough time to develop immunity. Earlier in the case of an epidemic of a dangerous disease, a large number of people died and the rest who survived the epidemic inherited the resistance to the progeny generations and as a result, resistent populations appeared. In our age, this is inhibited by the successful treatments. This means that the employment of the treating tools of our modern age is very useful for the man individually, saving the personal life; however, it is harmful for the species by not permitting the development of 
immunity and inheritance of resistance. Although immunity is as old as eukaryotic life [35], changes in its mechanisms can always happen.

The aforementioned facts are combined as follows: immunity after the reproductive age was not needed, as there was not a large population of aged people and new quick treatments inhibited the development of immunity before the reproductive age. The consequence of the combination of these two factors is the weakening of immunity to new antigens after reproduction (together the sustenance of immune memory) and (if we accept the outstanding role of immune system in longevity) therefore, the weakness of resistance in aged people to infectious and tumorous diseases results in their death. However, the long postreproductive lifespan could not be calculated by the evolution [36], as there was not similar case in the mammalian world (and earlier in man) and the change to the long post-reproductive life was very quick and it becomes more and more faster. There was (and is) not enough time for the program-like integration of the long post-reproductive lifespan into the mechanisms of the immune system. The conveyed evolution continously produces novel tools, which help the longevity, without the utilization of the immune system [37]. The average lifespan in many countries is around 80 years and the maximal lifespan could be more than 120 years for exceptional men, whose immune system together with the "tools" helped to survive infectious, degenerative, and tumorous diseases. As it was mentioned, 100 years ago, people were living till 40 years and at present, the mass of people are not living more than 40 years in Africa.

\section{The Thymus Pacemaker}

Thymus has a basic role in the immune system and in determining the longevity. It selects and kills the self-destructive lymphocytes, which help in the development of the organism up to the time of adolescence; however, after this period of life, thymus permits the erosion of the cells, as well as the intercellular materials, which leads to aging and later to the death of the organism. This general, continuous, and slow autoimmunity, which attacks the whole organism, is independent on the autoimmune diseases that are manifested in specific organs (e.g., rheumatoid arthritis, multiple scelerosis, lupus, etc.). There is a continuous attrition of the thymus also before puberty; however, after puberty, this becomes obvious, manifested in (morphologically visible) involution of the organ, which runs parallel to the deterioration of the immune system, together with its rearrangement, manifested in special organs [38]. The immune function of the thymus is regulated by the pineal gland, which is working under the direction of the brain; it seems to be likely that the primum mover of thymus pacemaker is in the suprachiasmatic 
nucleus, which is in direct neural and indirect chemical contact with the pineal gland $[39,40]$. Autoimmunity causes a slow, but continuous erosion of the components of the organism, which leads to the determination of lifespan, consequently longevity $[41,42]$. Without external interventions (bacterial or viral infections, accidents, etc.), the co-involution of pineal and thymus could cause the senescence of the immune system, the inflammaging, and death.

\section{Gender Differences in the Role of Immunity on Longevity}

The average human lifespan is increasing. At the beginning of the past century, it was 30 or 40 years in the more developed countries and now it is around 80 years. However, in the past and present alike, the lifespan of women was always higher. The difference in years is region- and country-dependent, i.e., in the United States (US) it is 6.7, in Great Britain 5.3, in Hungary 8.3, in Russia more than 12 , in India 0.6 , and in the neighboring country Bangladesh 0.1 . The numbers permit to guess that not only biological, but also social factors are influencing the differences; however, the female adventage is consequent. Studying the statistics of 178 countries, the female advantage was observed in 176. At present, the maximal human lifespan is 122 years and $90 \%$ of centenarians and supercentenarians are women. The question is: what is the explanation of this gender difference? As immunity has a dominant role in the resistance of inner and outer harmful aggression (infectious diseases, tumors, etc.), the causes of the gender differences are the first to be sought among all the differences of immune factors.

More XY chromosome-containing zygotes are existing after fertilization than XX-containing ones and therefore more boys are delivered than girls (105:100). However, this advantage is gradually decreasing and after the adolescent age, it is equalized and then it is passed to the advantage of women. Hormonal differences could be found in the reasons of it, as sexual hormones strongly influence the immune system and immune response abilities.

It was observed in animal experiments that the thymus transiently involutes during pregnancy and fully restores at the end of lactation [43]. It also atrophies after estrogen treatment [44]; however, testosterone treatment also causes thymic involution [45], which can be explained by the androgen-estrogen conversion in the body. This is due to the binding of excess estrogens by estrogen receptors (ER alpha and ER beta) [46], which can be found in a wide scale of immune cells [47]. B lymphopoiesis is also severely diminished during pregnancy [44]. This means that generally, estrogens are negative regulators of the immune system, while macrophage activity is stimulated by it [48], depending on the dose [49]. The loss of naive T-cells does not allow the action against new antigens and helps the 
proliferation of memory cells against old (earlier) antigens, which is characteristic to the elderly [50]. Hypogonadal state and androgen deficiency enhance the thymic output of T-cells [51], which also indicate the negative effect by androgens. Although the effect of sex hormones on immune system is unequivocal, the directions are controversial [52-55]. Innate immune cells are the first to get influenced; however, cells belonging to the adaptive immune system are also involved [56, 57]. The sex hormones can influence the immune system either directly or indirectly with the transmission of microbiome [58]. In addition to the negative effects of sexual hormones to the immune system, adrenal steroids are also able to trigger thymus involution [59]. In addition, hormones produced by the thymus itself (sex steroids, catecholamines, etc.) are also able to influence involution $[60,61]$. As estrogen and androgen receptors are present in developing immunocytes, the early exposure to sex hormones strongly influences the response to the sexual hormones in adulthood (hormonal imprinting) [62-64].

The involution of thymus starts in 1-year-old infants without gender differences and it continuously follows with a rate of $3 \%$ up to the middle age and with yearly $1 \%$ after that [65]. However, the number of thymic emigrant cells (CD3+ T-cells) is significantly higher in females than males and as a whole, female immune system is more robust compared with males [66]. In animal experiments, the thymic atrophy (involution) was slower in female mice compared with male ones and in 9-month-old mice CD3+ cells were present in higher number. Sexual hormones strongly influence the immune system and immune response abilities, rather in females than in males [67].

Accepting the aforementioned facts, it can be concluded that hormonal differences can be responsible for the immune-influenced longevity differences. However, other factors are not excluded (e.g., protection from mutant immunoregulatory genes on the $\mathrm{X}$ chromosome, because of double $\mathrm{X}$ chromosomes in women) [68]. Many social factors were disadvantageous for women in the past and also currently, a similar situation exists in certain regions. At the same time, globally, men's habitual characteristics (e.g., smoking, drinking, heavy physical work, etc.) can influence the immune system and also shorten the average life expectancy. However, the discussion of these factors is not the aim of this review.

\section{Probable Alterations in the Human Lifespan Caused by Modern-Age- Produced Exogeneous Chemicals and Phytoestrogens (Endocrine Disruptors)}

If steroid hormone receptors are present in the immune cells (and they have indeed), they also bind steroid-like molecules of exogeneous origin. The main representants of these molecules are the bisphenol A, vinclozoline, benzpyrene, 
dioxin, and phytoestrogens (e.g., soy genistein and daidzein). Bound to the members of steroid (intranuclear) hormone receptor superfamily (including estrogen receptors, androgen receptors, progesterone receptors, and retinoid receptors), they can activate them or inhibit the binding of the physiological hormone [69]. Consequently, they are able to stimulate or inhibit the physiological hormonal regulation. Their effect can be acute or long-lasting. The acute effect is an intervention into the normal hormonal regulation in adult and the long-lasting effect is dependent on the period of ontogenetic development. An interesting property of the endocrine disruptors is the occasional stronger effect of low doses, related to the higher ones. Finally, the manifestation of more autoimmune diseases was deduced to the exposure of endocrine disruptors [70, 71], and disease susceptibility and its transmission to the progenies also increased [72].

If the endocrine disruptors act during the early (embryonic) phase of intrauterine development, malformations of the sexual organs can be observed, such as cryptorchidism, hypospadias, and micropenis. However, there are very rare data on the effect to the immune system [73, 74]. This is understandable, as the immune effects are not directly manifested, they can be measured after birth, first of all in adult age. If the effect of endocrine disruptor is taking place perinatally, faulty hormonal imprinting develops with lifelong receptorial consequences [75]. This means that the function of immune system is seriously affected [76]. In addition, the faulty hormonal imprinting is inherited to the progenies [77, 78], its symptoms are manifested there too, and the repeated exposition by the same or similar faulty imprinters happens on the injured receptors. Faulty hormonal imprinting can also be provoked during adolescence, as it is also an imprinting-sensitive period of life [79, 80].

The faulty hormonal imprinting by endocrine disruptors is practically unavoidable, as these molecules are present in our foods (phytoestrogens and pesticides), in our plastic tools [81, 82], in the air, surronding us (e.g., benzpyrene and dioxin, by binding to the aryl hydrocarbon receptor), in our drinking water, in our pharmaceuticals (e.g., anticoncipient pills), etc., and considering only bisphenol A, as it is present in more than $90 \%$ of the US general population $[81,83]$ and was demonstrated in fetal serum and full-term amniotic fluid [84]. Nearly 4 billion kilogram of bisphenol A are produced yearly and utilized and more than 100,000 $\mathrm{kg}$ is released into the atmosphere.

\section{Pro-immunity and Antiaging}

Free radicals produced as end products of electron-transport chain destroy the plasma membrane and different important components of the cells, causing 
aging of them. This process has an outstanding role in the senescence of the immune system, as well as in the general aging and longevity (it is worthnoting that there are contradictory studies, e.g., [85], which emphasize the positive and signal function of free radicals [86, 87]). There is a built-in mechanism in the animal (human) organism, which protects the cells from the destruction using antioxidants such as superoxid dismutase and catalase and the balance between the oxidizing free radicals and physiological antioxidants determines the state of the system. However, there is a possibility to help fight against the oxidants, by the introduction of antioxidant compounds. Some vitamins are in the frontline of this battle.

Two vitamins have outstanding antioxidant effects, i.e., vitamins $\mathrm{C}$ and $\mathrm{E}$. Vitamin C (ascorbic acid) is water soluble and its effect is manifested inside the cells, whereas vitamin $\mathrm{E}$ is lipid soluble and its effect first save the plasma membrane. Both vitamins participate in the free radical trapping and in the suppression of pro-inflammatory genes influencing the innate and adaptive immune systems alike [88-91]. Telomere shortening is also suspended by them. Vitamin E improves T-cell functions [92] and T-cell proliferation [93, 94] by particularly reversing the decline of naive T-cell [95]. Vitamin E supplementation improves immune responsiveness by the decrease of lipid peroxidation products (such as PGE2) [96, 97] and helps the quick recovery of thymic atrophy, after X-ray irradiation [98].

Other vitamins, such as vitamins A and D, also have antioxidant effects and by this they influence immunity and longevity [99, 100]. However, these effects in our present knowledge - seem to be not so important as the effects of vitamins $\mathrm{C}$ and $\mathrm{E}$. There is such antiaging remedy, which dates back on thousands of years, such as ginseng [101], and are relatively new pharmaceuticals that have antiaging effects, such as selegiline (deprenyl) [102], which also have immunostimulant activity [103, 104].

There are also some pharmaceuticals that have pro-immune and antiaging effects. These are the rapamycin, rapalogs (derivatives of rapamycin), and metformin.

Rapamycin was originally isolated from Streptomyces hygroscopicus, which is indigenous in the Easter Islands and was used originally for declining immune response in the case of organ transplantation. However, later its robust immuneenhancing effect was also cleared [105]. Its target is the mammalian target of Rapamycin (mTOR), which is a serin/threonin kinase, encoded by the mTOR gene in men. Rapamycin, inhibiting mTOR enhances immune system and prolong lifespan [106-109].

Recognizing that hyperglycemia and hyperinsulinemia are important factors in aging and insulin-like growth factor 1 (IGF-1) is linked to longevity, it was supposed that caloric restriction has its beneficial (life-prolonging) effects 
through these factors [110]. Because of this, the antidiabetic drug, metformin, had been used for the extension of life. It is also a stimulant of the immune system [111, 112].

Lifespan is not equal with healthspan and many old people suffer by chronic diseases. This enhances the research of new antiaging and pro-immune compounds [113]. These can be calorie-restriction mimetics, autophagy inducers, senolytics, etc. [114]. This involves antiaging (and pro-immune) pharmacology, which is a rapidly developing discipline.

\section{Conclusions}

The immune system has a prominent role in the struggle against diseases both in younger and older age people and acute as well as chronic diseases frequently cause death. The resistance to common diseases weakens in older age and this works against longevity. From this point of view, strong immunity could be the prime mover of longevity and it weakens the cause of short lifespan [115]. In addition, the spontaneous involution of the thymus and the thymus-directed autoimmunity can also influence the lifespan, independent on infections or atritions. Antiaging (longevity-provoking) drugs are influencing the immune system and also promoting the supposition of the role of immune system in longevity. In addition, it must be considered that in the case of longevity, the immune system was studied very thoroughly and many-sided, whereas a lot of other systems were neglected. Therefore, it is difficult to declare that the secret of aging and longevity is hidden in the immune system, as the immune senescence can be a part of the general senecence of the organism, regulated by factors other than immune factors (brain, brain-regulated endocrine system, etc.) By all means, the immune system has a very important role in longevity, which does not disclose the participation of other systems or organs.

Although some researchers have grown enthusiastic about the presently accepted upper limit of human lifespan (122 years) and believe that it can be unlimited, death is unavoidable. However, the questions are: how and when. It seems to be very likely that the immune system can positively determine the "how," warranting healthspan, or negatively, producing autoimmunity, and its function is very important, especially when considering the continuously growing number of elderly people.

If we accept that the state of the immune system has a leading role in aging and lifespan, grave changes in longevity are expected by the extremely increasing number and variety of the endocrine disruptors [116], as well as by the new antiaging pharmaceuticals. However, the direction of the changes cannot be 
calculated at present. Considering that the alterations caused by the endocrine disruptors in the early periods of life are inherited to progenies, the perspectives seem to be more serious. However, theoretically, there is a possibility of transformation of the whole endocrine system under the bombardment by endocrine disruptors, which could also influence the human immunity and longevity alike, as the integration of some endocrine disruptors into the human endocrine system is imaginable, as probably it was in the case of lipid-soluble vitamins (exohormones) [117, 118].

\section{Conflict of Interest}

None.

\section{References}

1. Wick, G., Grubeck-Loevenstein, B.: The aging immune system: Primary and secondary alterations of immune reactivity in the elderly. Exp Gerontol 32, 401-413 (1997).

2. De la Fuente, M.: Role of neuroimmunomodulation in aging. Neuroimmunomodulation 15, 213-223 (2008).

3. Martinez de Toda, I., Maté, I., Vida, C., Cruces, J., De la Fuente, M.: Immune function parameters as markers of biological age and predictors of longevity. Aging (Albany) 8 , 3110-3119 (2016).

4. Alonso-Fernadez, P., De la Fuente, M.: Role of the immune system in aging and longevity. Curr Aging Sci 4, 78-100 (2011).

5. Aspinall, R.: Longevity and the immune response. Biogerontology 1, 273-278 (2000).

6. Gruver, A. L., Hudson, L. L., Sempowski, G. D.: Immunosenescence of aging. J Pathol 211, 144-156 (2007).

7. Turner, J. E.: Is immunosenescence influenced by our lifetime "dose" of exercise? Biogerontology 17, 581-602 (2116).

8. Weyand C. M., Goronzy, J. J.: Aging of the immune system. Mechanisms and therapeutic targets. Ann Am Thorac Soc 13, S422-S428 (2016).

9. Lehtonen, L., Eskola, J., Vainio, O., Lehtonen, A.: Changes in lymphocyte subsets and immune competence in very advanced age. J Gerontol 45, M108-M112 (1990).

10. Pawelec, G.: Does the human immune system become "senescent"? F1000Res 6, 1323 (2017).

11. Ongrádi, J., Stercz, B., Kövesdi, V., Vértes, L.: Immunosenescence and vaccination of the elderly, I. Age-related immune impairmant. Acta Microbiol Immunol Hung 56, 199-210 (2009).

12. Ongrádi, J., Stercz, B., Kövesdi, V., Vértes, L.: Immunosenescence and vaccination of the elderly, II. New strategies to restore age-related immune impairment. Acta Microbiol Immunol Hung 56, 301-312 (2009).

13. Ongrádi, J., Kövesdi, V.: Factors that may impact on immunosenescence: An appraisal. Immun Ageing 14, 7 (2010). 
14. Ongrádi, J., Kövesi, V.: Numerical alterations of aging B lymphocyte subsets. Acta Physiol Hung 98, 99-104 (2011).

15. Weiskopf, D., Weinberger, B., Grubeck-Loebenstein, B.: The aging of the immune system. Transpl Int 22, 1041-1050 (2009).

16. Franceschi, C., Monti, D., Barbieri, D., Salvioli, S., Grassilli, E., Troiano, L., Capri, M., Guido, M., Bonafé, M., Tropea, F., Salomoni, P., Benatti, F., Bellesi, E., Macchioni, S., Anderlini, L., Sansoni, P., Mriotti, S., Wratten, M. L., Tetta, C., Cossarizza, A.: Successful immunosenescence and the remodelling of immune responses with aging. Nephrol Dial Transplant 11, 18-25 (1998).

17. Ginaldi, L., De Martinis, M., D’Ostilio, A, Marini, L., Loreto, M. F., Quaglino, D.: The immune system in elderly: III. Innate immunity. Immunol Res 20, 117-126 (1999).

18. Colonna-Romano, G., Bulati, M., Aquino, A., Vitello, S., Lio, D., Candore, G., Caruso, C.: B cell immunosenescence in the elderly and in centenarians. Rejuvenation Res 11, 433-439 (2008).

19. Linchan, E., Fitzgerald, D. C.: Ageing and immune system: Focus on macrophages. Eur J Microbiol Immunol 5, 14-24 (2015).

20. Bauer, M. E.: Chronic stress and immunosenescence: A review. Neuroimmunomodulation 15, 241-250 (2008).

21. Pinti, M., Nasi, M., Lugli, E., Gibellini, L., Bertoncelli, L., Roat, E., De Biasi, S., Mussini, C., Cossarizza, A.: T cell homeostasis in centenarians: From the thymus to the periphery. Curr Pharm Des 16, 587-603 (2010).

22. Monti, D., Ostan, R., Borelli, V., Castellani, G., Franceschi, C.: Inflammaging and human longevity in the omics era. Mech Ageing Dev 165, 129-138 (2017).

23. Paolisso, G., Barbieri, M., Bonafé, M., Franceschi, C.: Metabolic age modelling: The lesson from centenarians. Eur J Clin Invest 30, 888-894 (2000).

24. Ginaldi, L., De Martinis, M., D’Ostilio, A., Marini, L., Loreto, M. F., Corsi, M. P., Quaglino, D.: The immune system in the elderly: I. Specific humoral immunity. Immunol Res 20, 101-108 (1999).

25. Fuentes, E., Fuentes, M., Alarcon, M., Palomo, I.: Immune system dysfunction in the elderly. An Acad Bras Cienc 89, 1678 (2017).

26. Sansoni, P., Vescovini, R., Fagnoni, F., Biasini, C., Zanni, F., Zanlari, L., Telera, A., Lucchini, G., Passeri, G., Monti, D., Franceschi, C., Passeri, M.: The immune system in extreme longevity. Exp Gerontol 43, 61-65 (2008).

27. Dewan, S. K., Zheng, S. B., Xia, S. J., Bill, K.: Senescent remodelling of the immune system and its contribution to the predisposition of the elderly to infections. Chin Med J 125, 3325-3331 (2012).

28. Minciullo, P. L., Catalano, A., Mandraffino, G., Casciaro, M., Crucitti, A., Maltese, G., Morabito, N., Lasco, A., Gangemi, S., Basile, G.: Inflammaging and anti-inflammaging: The role of cytokines in extreme longevity. Arch Immunol Ther Exp 64, 111-126 (2016).

29. De la Fuente, M.: Effects of antioxidants on immune system ageing. Eur J Clin Nutr 56, 5-8 (2002).

30. Sanz, A., Pamplona, R., Barja, G.: Is the mitochondrial free radical theory intact? Antiox Redox Signal 8, 582-599 (2006).

31. Hertoghe, T.: The "multiple hormone deficiency" theory of aging: Is human senescence caused mainly by multiple hormone deficiencies? Ann N Y Acad Sci 1057, 448-465 (2005). 
32. De la Fuente, M.: Role of the immune system in aging. Immunologia 27, 176-191 (2008).

33. Ostan, R., Bucci, L., Capri, M., Salvioli, S., Scurti, M., Pini, E., Monti, D., Francheschi, C.: Immunosenescence and immunogenetics of human longevity. Neuroimmunomodulation 15, 224-240 (2008).

34. Csaba, G.: Thoughts on the cultural evolution of man. Developmental imprinting and transgenerational effect. Riv Biol 100, 461-474 (2007).

35. Csaba, G.: Complex multicellular functions at a unicellular eukaryote level: Learning, memory and immunity. Acta Microbiol Immunol Hung 64, 105-120 (2017).

36. Francheschi, C., Bonafé, M., Valensin, S., Olivieri, F., De Luca, M., Ottaviani, E., De Benedictis, G.: Inflamm-aging. An evolutionary perspective on immunosenescence. Ann N Y Acad Sci 908, 244-254 (2000).

37. Fougére, B., Boulanger, E., Nourhashémi, F., Guyonnet, S., Cesari, M.: Chronic inflammation: Accelerator of biological aging. J Gerontol A Biol Sci Med 72, 1218 1225 (2017).

38. Csaba, G.: The immunoendocrine thymus as a pacemaker of lifespan. Acta Microbiol Immunol Hung 63, 139-158 (2016).

39. Csaba, G.: The role of brain-pineal-thymus system in the determination of lifespan: The autoimmune aging theory. Adv Neuroimmune Biol 6, 139-148 (2017).

40. Csaba, G.: The pineal regulation of the immune system: 40 years since the discovery. Acta Microbiol Immunol Hung 60, 77-91 (2013).

41. Pfister, G., Savino, W.: Can the immune system still be efficient in the elderly? An immunological and immunoendocrine therapeutic perspective. Neuroimmunomodulation 15, 351-364 (2008).

42. Aspinall, R., Pitts, D., Lapenna, A., Mitchell, W.: Immunity in the elderly: The role of the thymus. J Comp Pathol 142, S111-S115 (2010).

43. Bodey, B., Bodey, B., Jr., Siegel, S. E., Kaiser, H. E.: Involution of the mammalian thymus, one of the leading regulators of aging. In Vivo 11, 421-440 (1997).

44. Kincade, P. W., Medina, K. L., Smithson, G.: Sex hormones as negative regulators of lymphopoesis. Immunol Rev 137, 119-134 (1994).

45. Oner, H., Ozan, E.: Effects of gonadal hormones on thymus gland after bilateral ovariectomy and orchidectomy in rats. Arch Androl 48, 115-126 (2002).

46. Erlandsson, M. C., Ohlsson, C., Gustafsson, J. A., Carlsten, H.: Role of oestrogen receptors alpha and beta in immune organ development and in oestrogen-mediated effects of thymus. Immunology 103, 17-25 (2001).

47. Törnwall, J., Carey, A. B., Fox, R. I., Fox, H. S.: Estrogen in autoimmunity: Expression of estrogen receptors in thymic and autoimmune T cells. J Gend Specif Med 2, 33-40 (1999).

48. Csaba, G.: Is there a hormonal regulation of phagocytosis at unicellular and multicellular levels? A critical review. Acta Microbiol Immunol Hung 64, 357-372 (2017).

49. Forsberg, J. G.: Short-term and long-term effects of estrogen on lymphoid tissues and lymphoid cells with some remarks on the significance for carcinogenesis. Arch Toxicol 55, 79-90 (1984).

50. Hince, M., Sakkal, S., Vlahos, K., Dudakov, J., Boyd, R., Chedgey, A.: The role of sex steroids and gonadectomy in the control of thymic involution. Cell Immunol 252, 122-138 (2008).

51. Olsen, N. J., Kovacs, W. J.: Evidence that androgens modulate human T cell output. J Invest Med 59, 32-35 (2011). 
52. Ahmed, S. A., Talal, N.: Sex hormones and the immune system - Part 2. Animal data. Baillieres Clin Rheumatol 4, 13-31 (1990).

53. Verthelyi, D.: Sex hormones as immunomodulators in health and disease. Int Immunopharmacol 1, 983-993 (2001).

54. Hughes, G. C., Clark, E. A.: Regulation of dendritic cells by female sex steroids: Relevance to immunity and autoimmunity. Autoimmunity 40, 470-481 (2007).

55. Janssson, L., Holmdahl, R.: Estrogen-mediated immunosuppression in autoimmune diseases. Inflamm Res 47, 290-301 (1998).

56. Kovats, S., Carreras, E.: Regulation of dendritic cell differentiation and function by estrogen receptor ligands. Cell Immunol 252, 81-90 (2008).

57. Jaillon, S., Berthenet, K., Garlanda, C.: Sexual dimorphism in innate immunity. Clin Rev Allergy Immunol (2017). doi:10.1007/s12016-017-8648-x [Epub ahead of print].

58. Dumont-Lagacé, M., St-Pierre, C., Perreault, C.: Sex hormones have pervasive effects on thymic epithelial cells. Sci Rep 5, 12895 (2015).

59. Goya, R. G.: Hormones, genetic program and immunosenescence. Exp Clin Immunogenet 9, 188-194 (1992).

60. Csaba, G.: Hormones in the immune system and their possible role. A critical review. Acta Microbiol Immunol Hung 61, 241-260 (2014).

61. Leposavic, G., Perisic, M.: Age associated remodeling of thymopoiesis: Role for gonadal hormones and catecholamines. Neuroimmunomodulation 15, 291-322 (2008).

62. Csaba, G.: The present and future of human sexuality: Impact of faulty perinatal hormonal imprinting. Sex Med Rev 5, 163-169 (2017).

63. Csaba, G.: The faulty perinatal hormonal imprinting as functional teratogen. Curr Pediatr Rev 12, 222-229 (2016).

64. Martin, J. T.: Sexual dimorphism in immune function: The role of prenatal exposure to androgens and estrogens. Eur J Pharmacol 29, 251-261 (2000).

65. Pido-Lopez, J., Imami, N., Aspinall, R.: Both age and gender affect thymic output: More recent thymic migrants in females than males as they age. Clin Exp Immunol 125, 409-413 (2001).

66. Khan, D., Ansar Ahmed, S.: The immune system is a natural target for estrogen action: Opposing effects of estrogen in two prototypical autoimmune diseases. Front Immunol 6, 635 (2016).

67. Aspinall, R., Andrew, D.: Gender-related differences in the rate of age associated thymic atrophy. Dev Immunol 8, 95-106 (2001).

68. Purtilo, D. T., Sullivan, J. L.: Immunological bases for superior survival of females. Am J Dis Child 133, 1251-1253 (1979).

69. Kiyama, R., Wada-Kiyama, Y.: Estrogenic endocrine disruptors: Molecular mechanism of action. Environ Int 83, 11-40 (2015).

70. Kharrazian, D.: The potential role of bisphenol A (BPA) pathogenesis in autoimmunity. Autoimmune Dis 2014, 743616 (2014).

71. Jochmanova, I., Lazúrová, Z., Rudnay, M., Bacová, I., Mareková, M., Lazúrové, I.: Environmental estrogen bisphenol A and autoimmunity. Lupus 24, 392-399 (2015).

72. Jirtle, R. L., Skinner, M. K.: Environmental epigenomics and disease susceptibility. Nat Rev Genet 8, 253-262 (2007).

73. Schug, T. T., Janesick, A., Blumberg, B., Heindel, J. J.: Endocrine disrupting chemicals and disease susceptibility. J Steroid Biochem Mol Biol 127, 204-215 (2011). 
74. Khan, D., Ansar Ahmed, S.: Epigenetic regulation of non-lymphoid cells by biphenol A, a model endocrine disrupter: Potential implications for immunoregulation. Front Endocrinol 6, 91 (2015).

75. Csaba, G.: Immunoendocrinology: Faulty hormonal imprinting in the immune system. Acta Microbiol Immunol Hung 61, 89-106 (2014).

76. Csaba, G.: Effect of endocrine disruptor phytoestrogens on the immune system: Present and future. Acta Microbiol Immunol Hung 65, 1-14 (2018).

77. Dietert, R. R.: Transgenerational epigenetics of endocrine disrupting chemicals. In Tollefsbol, T. (ed): Transgenerational Epigenetics. Academic Press, Cambridge, MA, 2014, pp. 239-254.

78. Csaba, G.: Transgenerational effects of perinatal hormonal imprinting. In Tollefsbol, T. (ed): Transgenerational Epigenetics. Academic Press, Cambridge, MA, 2014, pp. 255-267.

79. Csaba, G., Inczefi-Gonda, Á.: Anabolic steroid (nandrolone) treatment during adolescence decreases the number of glucocorticoid and estrogen receptors in adult female rats. Horm Metab Res 25, 353-355 (1993).

80. Gaál, A., Csaba, G.: Testosterone and progesterone level alterations in the adult rat after retinoid (retinol or retinoic acid) treatment (imprinting) in neonatal or adolescent age. Horm Metab Res 30, 487-489 (1998).

81. Vandenberg, L. N., Hauser, R., Marcus, M., Olea, N., Welshons, W. V.: Human exposure to bisphenol A (BPA). Reprod Toxicol 24, 139-177 (2007).

82. Rubin, B. S.: Bisphenol A: An endocrine disruptor with widespread exposure and multiple effects. J Steroid Biochem Mol Biol 127, 27-34 (2011).

83. Calafat, A. M., Ye, X., Wong, L. Y., Reidy, J. A., Needham, L. L.: Exposure of the U.S. population to bisphenol A and 4-tertiary-octylphenol: 2003-2004. Environ Health Perspect 116, 39-44 (2008).

84. Ikezuki, T., Tsutsumi, O., Takay, Y., Kamey, Y., Taketani, Y.: Determination of bisphenol A concentrations in human biological fluids reveals significant early prenatal exposure. Hum Reprod 17, 2839-2841 (2002).

85. Vina, J., Borras, C., Abdelaziz, K. M., Garcia-Valles, R., Gomes-Cabrera, M. C.: The free radical theory of aging revisited: The cell signaling theory of aging. Antioxid Redox Signal 19, 779-787 (2013).

86. Barja, G.: Free radicals and aging. Trends Neurosci 27, 595-600 (2004).

87. Knight, J. A.: Review: Free radicals, antioxidants, and the immune system. Ann Clin Lab Sci 30, 145-158 (2000).

88. Monacelli, F., Acquarone, E., Giannotti, C., Borghi, R., Nencioni, A.: Vitamin C, aging and Alzheimer disease. Nutrients 9, E670 (2017).

89. Penn, N. D., Purkins, L., Kelleher, J., Heatley, R. V., Mascle-Taylor, B. H., Belfield, P. W.: The effect of dietary supplementation with vitamins A, C, and E on cell-mediated immune function in elderly long-stay patients: A randomized controlled trial. Age Ageing 20, 169-174 (1991).

90. Seraffini, M.: Dietary vitamin E and T cell-mediated function in the elderly: Effectiveness and mechanism of action. Int J Dev Neurosci 18, 401-410 (2000).

91. Beharka, A., Reedican, S., Leka, L., Meydani, S. M.: Vitamin E status and immune function. Methods Enzymol 282, 247-263 (1997).

92. Han, S. N., Adolfsson, O., Lee, C. K., Prolla, T. A., Ordovas, J., Meydani, S. N.: Age and vitamin E-induced changes in gene expression profiles of T cells. J Immunol 177, 60526061 (2006). 
93. Moriguchi, S.: The role of vitamin E in T-cell differentiation and the decrease of cellular immunity with aging. Biofactors 7, 77-86 (1998).

94. Moriguchi, S., Kaneyasu, M.: Role of vitamin E in immune system. J Clin Biochem Nutr 34, 97-109 (2003).

95. Wu, D., Meydani, S. N.: Age associated changes in immune inflammatory responses: Impact of vitamin E intervention. J Leukoc Biol 84, 900-914 (2008).

96. Wu, D., Meydani, S. N.: Age-associated changes in immune function: Impact of vitamin E intervention and underlying mechanisms. Endocr Metab Immune Disord Drug Targets 14, 283-289 (2014).

97. Meydani, S. N., Barklund, M. P., Liu, S., Meydani, M., Miller, R. A., Cannon, J. G., Morrow, F. D., Rocklin, R., Blumberg, J. B.: Vitamin E supplementation enhances cellmedited immunity in healthy elderly subjects. Am J Clin Nutr 52, 557-563 (1990).

98. Moriguchi, S., Muraga, M.: Vitamin E and immunity. Vitam Horm 59, 315-336 (2000).

99. Castellani, M. L., Shaik-Dhastagirisaheb, Y. B., Tripodi, D., Anogeinaki, A., Felaco, P., Toniato, E., De Lutiis, M. A., Fulchen, M., Teté, S., Galzio, R., Salini, V., Caraffa, A., Antinolfi, P., Frydas, I., Sabatino, G., Kempurai, D.: Interrelationship between vitamins and cytokines in immunity. J Biol Regul Homeost Agents 24, 385-390 (2010).

100. Goncalves de Carvalho, C. M., Ribeiro, S. M.: Aging, low-grade systemic inflammation and vitamin D: A mini-review. Eur J Clin Nutr 71, 434-440 (2017).

101. Yang, Y., Ren, C., Zhang, Y., Wu, X.: Ginseng: An nonnegligable natural remedy for healthy aging. Aging Dis 8, 708-720 (2017).

102. Knoll, J., Miklya, I.: Longevity study with low doses of selegiline (-)-deprenyl and (2R)(1-benzofuran-2-yl)-N-propylpentane-2-amine (BPAP). Life Sci 167, 32-38 (2016).

103. Müller, T. H., Kuhn, W., Krüger, R., Przuntek, H.: Selegiline as immunostimulant - A novel mechanism of action? J Neural Transm 52, 321-328 (1998).

104. Thyagarajan, S., Madden, K. S., Boehm, G. W., Stevens, S. Y., Felten, D. L., Bellinger, D. L.: L-Deprenyl reverses age-associated decline in splenic norepinephrine, interleukin-2 and interferon-y production in old female F344 rats. Neuroimmunomodulation 20, 72-78 (2013).

105. Bravo-San Pedro, J. M., Senovilla, L.: Immunostimulatory activity of lifespan-extending agents. Aging (Albany) 5, 793-801 (2013).

106. Mannick, J. B., Del Giudice, G., Lattanzi, M., Valiante, N. M., Praestgaard, J., Huang, B., Lonetto, M. A., Maecker, H. T., Kovarik, J., Carson, S., Glass, D. J., Klickstein, L. B.: mTOR inhibition improves immune function in the elderly. Sci Transl Med 6, 268ra179 (2014).

107. Blagosklonny, M. V.: Rejuventing immunity: "Anti-aging drug today" eight yers later. Oncotarget 6, 19405-19412 (2015).

108. Blagosklonny, M. V.: Rapamycin and quasi-programmed aging: Four years later. Cell Cycle 9, 1859-1862 (2010).

109. Blagosklonny, M. V.: From rapalogs to anti-aging formula. Oncotarget 8, 35492-35507 (2017).

110. Anisimov, V. N.: Metformin for aging and cancer prevention. Aging 2, 760-774 (2010).

111. Bashmakov, Y. K., Petyaev, I. M.: Old drug acquires new target: Metformin and SIRT1. J Diabetes Metab 2, 107e (2011).

112. Anisimov, V. N.: Metformin: Do we finally have an anti-aging drug? Cell Cycle 12, 3483-3489 (2013). 
113. Vaiserman, A. M., Lushchak, O. V., Koliada, A. K.: Anti-aging pharmacology: Promises and pitfalls. Ageing Res Rev 31, 9-35 (2016).

114. Ito, K., Colley, T., Mercado, N.: Geroprotectors as a novel therapeutic strategy for COPD, an accelerating aging disease. Int J Chron Obstruct Pulmon Dis 7, 641-652 (2012).

115. Bektas, A., Schurman, S. H., Sen, R., Ferrucci, L.: Human T cell immunosenescence and inflammation in aging. J Leukoc Biol 102, 977-988 (2017).

116. Csaba, G.: The role of endocrine disruptors in future human evolution: The ED-exohormone system. Theor Biol Forum (2018). [Epub ahead of print].

117. Csaba, G.: Faulty perinatal hormonal imprinting caused by exogeneous vitamin D - Dangers and problems. Austin J Nurtr Food Sci 4, 1075-1078 (2016).

118. Csaba, G.: Vitamin-caused faulty perinatal hormonal imprinting and its consequences in adult age. Physiol Int 104, 217-225 (2017). 